University of Rhode Island

DigitalCommons@URI

Open Access Master's Theses

1990

\title{
Lexical Acquisition in Skilled and Less Skilled Readers
}

Linda Aguiar

University of Rhode Island

Follow this and additional works at: https://digitalcommons.uri.edu/theses

\section{Recommended Citation}

Aguiar, Linda, "Lexical Acquisition in Skilled and Less Skilled Readers" (1990). Open Access Master's Theses. Paper 936.

https://digitalcommons.uri.edu/theses/936

This Thesis is brought to you for free and open access by DigitalCommons@URI. It has been accepted for inclusion in Open Access Master's Theses by an authorized administrator of DigitalCommons@URI. For more information, please contact digitalcommons-group@uri.edu. 
LEXICAL ACQUISITION IN SKILLED AN LESS SKILLED READERS BY

LINDA AGUIAR

A THESIS SUBMITTED IN PARTIAL FULFILLMENT OF THE REQUIREMENTS FOR THE DEGREE OF MASTER OF ARTS

IN

PSYCHOLOGY

UNIVERSITY OF RHODE ISLAND

1990 


\section{MASTER OF ARTS THESIS \\ OF}

\section{LINDA AGUIAR}

\section{APPROVED :}

Thesis Committee
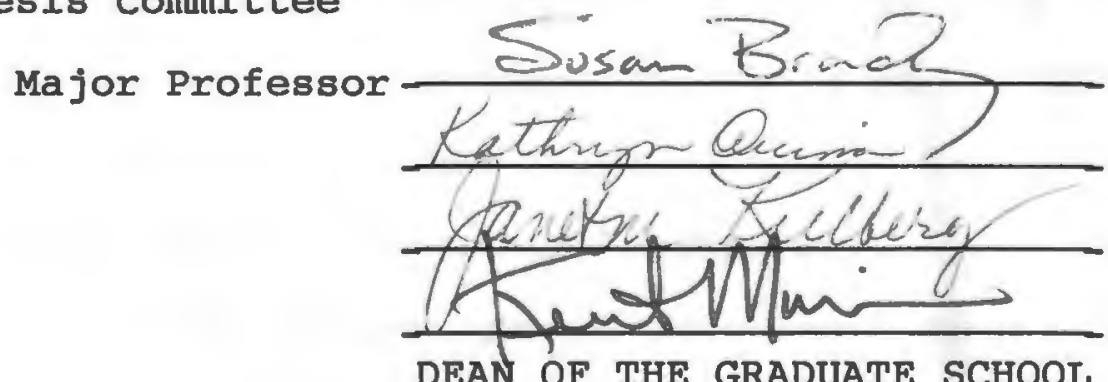


\section{ABSTRACT}

Lexical acquisition ability was studied in fourth grade children through use of a paired associate design. Reading achievement predicted ability to learn words more highly than did other factors, including estimated I.Q., and shortterm memory did not. Examination of two subgroups of skilled and less skilled readers indicated that less skilled readers had more difficulty in acquiring new words. Less skilled readers made more errors and required more trials than did skilled readers. Less skilled readers also achieved lower scores on measures of short and long term recognition of the word's referents. No differences in rate of forgetting over time were found between groups. No between group differences were found in the ability to provide definitions for the newly learned words. No significant differences between groups were found on a measure of incidental word learning. 


\section{ACKNOWLEDGEMENTS}

I am especially grateful to Dr. Susan Brady, my major professor for her interest, guidance and support throughout the course of events which led to the completion of this study. I also wish to thank Dr. Janet Kulberg for her valuable insights and comments.

Very special thanks are extended to research assistants, Judith Cicero, Janice Ruggeri and Linda stoler, for their invaluable assistance in collecting data and scoring protocols. Their dedication, precision, and support were fully appreciated.

In addition, I would like to thank the Tiverton Public School System, the co-operative principles, teachers, and staff who made this work possible by contributing the use of their facilities and time. The greatest appreciation is extended to the children who participated in this study, as well as to their parents. 
TABLE OF CONTENTS

ABSTRACT

ACKNOWLEDGEMENTS $\quad$ iii

$\begin{array}{ll}\text { INTRODUCTION } & 1\end{array}$

Background 1

$\begin{array}{ll}\text { Present Study } & 4\end{array}$

$\begin{array}{ll}\text { METHOD } & 7\end{array}$

$\begin{array}{ll}\text { Subjects } & 7\end{array}$

$\begin{array}{ll}\text { Materials } & 8\end{array}$

$\begin{array}{lr}\text { Procedure } & 10\end{array}$

$\begin{array}{ll}\text { Scoring } & 13\end{array}$

$\begin{array}{lr}\text { RESULTS } & 16\end{array}$

$\begin{array}{ll}\text { DISCUSSION } & 23\end{array}$

$\begin{array}{ll}\text { APPENDICES } & 31\end{array}$

Appendix A, Tables 31

Appendix B, Training Proceedure 37

Appendix C, Journey Game $\quad 42$

$\begin{array}{ll}\text { BIBLIOGRAPY } & 46\end{array}$ 


\section{INTRODUCTION}

Background. In the study of reading disability it has become increasingly apparent that in most cases this is a language based disorder. Reading disabled children have been shown to differ from their peers on a number of diverse language skills. These include differences in phonological processing abilities (Liebermann \& Shankweiler, 1985; Vellutino, 1979; Wagner \& Torgesen, 1987), in syntactic abilities (Jordan, 1988; Morice \& Slaugis, 1985; Vogel, 1975) and in pragmatic use of language (Donahue, 1984).

These observed differences in linguistic capabilities have led us to speculate about lexical acquisition and vocabulary knowledge in the reading disabled child. As might be expected, vocabulary differences between groups of reading disabled children and their normally achieving peers have been found (Kail \& Leonard, 1986; Vellutino \& Scanlon, 1987). In comparing groups that had been used for research studies, Vellutino and Scanlon (1987) noted that the reading disabled groups consistently scored lower than the non-disabled groups on measures of both productive and receptive vocabulary measures. These group differences remained even when the groups were matched on a non-verbal I.Q. measure.

At least two hypotheses can be generated concerning lexical acquisition by reading disabled students. One hypothesis states that the reading disabled child reads less than the good reader and therefore learns fewer new words. 
vocabulary differences are found in very young disabled readers, however, raising doubt as to whether this explanation can be sufficient.

A second hypothesis states that the observed difference in vocabulary is due to a difficulty learning new words because of a deficit in phonological processing and related linguistic abilities. This explanation has a strong theoretical and empirical basis. Learning a new word requires accurate perception, storage, and retrieval of the word. Each of these processes has been shown to differentiate good from poor readers, as will be discussed.

First, results indicate that poor readers are deficient in speech perception (e.g. Godfrey, Syrdal-Lasky, Millay, \& Knox, 1981; Snowling, Goulandris, Bowlby, \& Howell, 1986; Werker \& Tees, 1987). In a study of speech perception using good and poor readers, it was found that the poor readers were less accurate at identifying speech sounds masked in noise. In contrast, when environmental sounds were presented in noise, differences between the groups did not emerge (Brady, Shankweiler, \& Mann, 1983). Furthermore, good and poor readers have been shown to differ in speech perception under normal conditions as well (Brady, Poggie, \& Rapala, in press; Catts, 1986; Rapala \& Brady, in press; Snowling, 1981).

Second, poor readers demonstrate deficiencies in verbal short-term memory tasks (Brady, 1986; Brady, Shankweiler, \& Mann, 1983; Jorm, 1983; Katz \& Liebermann, 1981; Liebermann, Mann, Shankweiler, \& Werfelman, 1982). Analysis of errors in 
short-term memory measures indicate that poor readers use a phonological coding strategy as do good readers; poor readers, however, do so less skillfully (Brady, Mann, \& Schmidt, 1987; Katz et al., 1981; Vellutino, Scanlon, \& Tanzman, 1988).

Third, reading disabled children also exhibit difficulty with word retrieval in rapid naming tasks and tasks of lexical access (Denckla \& Rudel, 1976a, 1976b; Rudel, Denckla, \& Broman, 1978; Wolf, 1982, 1984; Wolf, Bally, \& Morris, 1986). Poor readers are found to be slower and less accurate at retrieving the correct words when performing these tasks.

In sum, reading disabled children are deficient on a variety of phonological tasks that tap perceptual, storage, and retrieval processes. In the currently popular framework of a limited-capacity working memory system (Baddeley, 1976: Perfetti, 1986), it is plausible that deficits in any of these could lessen the efficiency and accuracy of verbal processing. This has logical consequences for tasks which are dependent on verbal processing, such as word acquisition. Indeed, a subject with severe deficiencies in phonological storage was also found to be extremely deficient in a task of learning new words for known concepts (Baddeley, Papagno, \& Vallar, 1988). In addition, in a longitudinal study of pre-readers, a positive correlation emerged between phonological short-term memory at age 4 and vocabulary gain at age 5. (Gathercole \& Baddeley, 1989). There is also preliminary evidence that reading disabled children experience difficulty in learning new words. Nelson and Warrington (1980) found that a group 
of dyslexic children produced more errors than a control group in a task of vocabulary learning.

When the observed reading group differences in vocabulary are considered in light of this research, the hypothesis that they are due to reading experience becomes less tenable. This is not to deny the probability that some of the observed difference in vocabulary may occur as a result of differences in exposure to text; children certainly expand vocabulary through reading (Jenkins, Stein, \& Wysocki, 1984; Nagy, Anderson, \& Herman, 1987). But this is an explanation which seems too simplistic in that it does not take into account the linguistic factors which can be expected to influence the learning of new words.

Lack of awareness of these other factors which could impinge on word learning could lead to the assumption that the reading disabled child should be just as quick as the nondisabled child to learn new words presented aurally. This could result in unrealistic expectations for both children with reading problems and their teachers. In addition, it would preclude the development of teaching techniques to specifically address the problems of these children in learning new vocabulary items. Therefore it is important to verify whether differences in lexical acquisition are evident for poor readers under listening conditions.

The Present Study. This study examined the ability of fourth grade children to acquire aurally presented words. The following measures were used to assess learning new words: 
errors during training, trials to criterion, ability to define new words, recall of new words, and recognition of new words. The predictor factors considered in learning words were intelligence, short-term memory, and reading ability. Subgroups of skilled and less-skilled readers were compared on the measures of word learning.

Word learning was studied under two conditions. A directed word learning condition created a situation in which the children directly and purposefully attempted to acquire new words. This is analogous to the learning of vocabulary words in a classroom setting. In an incidental learning condition the fast-mapping abilities of the children were assessed. Fast mapping, hypothesized as the usual method by which young children acquire new words, is an association of the phonological, syntactic, and semantic features of a newly encountered word. These features are mapped together, potentially in an incomplete form, and entered int the lexicon. The process can occur with a single exposure to a word and explicit instruction or direction to notice the word need not be present (Carey, 1978).

To test the hypothesis that less skilled readers learn words differently from their skilled reader peers, children in both groups were introduced to six new words which were deliberately taught and learned, as well as to two words which were incidentally learned. These words were nonsense words which were devised specifically for this study.

Several aspects of word learning were compared between 
the two groups including:

1) number of trials necessary for learning to criterion (directed learning condition only)

2) number of errors in the training session (directed learning condition only)

3) number of features of definitions remembered (directed learning condition only)

$4)$ short-term recall of the words

5) short-term recognition

6) long-term recognition (one to two weeks after learning the words )

It was predicted that when the groups were compared: 1) the less skilled reading group would require more trials to learn the words to criterion

2) the less skilled reading group would make more errors during the training session

3) the less skilled group would be less accurate in short-term recall of the words

$4)$ the less skilled group would be less accurate in short-term recognition of the words

5) the less skilled group would be less accurate in longterm recognition of the words 
METHOD

Subjects. Subjects were fourth grade students from four classes (two schools) in a school system in a suburban area of north-eastern Rhode Island. Letters to parents describing the study and requesting their child's participation were sent home through the schools, via the children. A total of sixtyeight informed consent forms were returned to the school. All children who brought in a signed form were allowed to participate in all sessions of the study. At the beginning of each session children were asked if they wished to continue as participants.

An age range limit of 9 years, 5 months to 10 years, 6 months was selected as a criterion for inclusion in the study. (These limits allowed inclusion of only those children who would have started school at the ages recommended by the school department in that district). Subjects were required to have English as their first language, and have no known speech or auditory handicaps. In addition, children selected for inclusion scored within the average range on the Block Design Subtest of the Wechsler Intelligence Scale for Children-Revised and were within normal limits on either the Peabody Picture Vocabulary or a short form of the WISC-R. Subjects who had a high score on one measure of I.Q. (PPVT and WISC-R), but were within an average range on the other measure were therefore included. Nine potential subjects were dropped from the final analysis because of failure to meet one or more points of the above criteria. One additional subject was 
dropped from the final analysis because of incomplete data.

Reading groups were formed by using two subtest scores, Word Identification (ID) and word Attack (ATTACK) from the Woodcock Reading Mastery Test. Children were ranked according to their scores on these subtests. If a child ranked in the top third of the scores on both subtests, the child was included in the skilled reader group. If a child ranked in the bottom third on both reading measures, the child was included in the less skilled reading group. Using this method, 12 children fell into the skilled reader group and 10 children fell into the less skilled reader group. The two groups had non-overlapping scores on each of the two reading measures .

Materials

Predictor Measures. As noted above, the word Identification and Word Attack subtests of the Woodcock Reading Mastery test were administered in order to select children for the two reading groups. These subtests were selected because decoding measure correlate highly with comprehension; therefore, they are an appropriate estimate of reading level. The Word Identification task has a reported reliability of .98 . The reliability reported for the word Attack measure is .97 .

A control measure of non-verbal I.Q., the Block Design Subtest of the WISC-R, was administered. For this age group, this subtest has a reported reliability of .80 and a correlation of .71 with the Full Scale I.Q.. 
A measure of short-term verbal memory, the Digit span Subtest of the WISC-R (DIGIT), was administered to all subjects. To explore the relationship between short-term memory and word learning, the scores from this subtest were used in correlations with the outcome variables. For this age group, Digit Span has a reported reliability of . 71 .

Two vocabulary measures assessed achieved vocabulary. One measure was the Vocabulary Subtest of the WISC-R (VOCAB). This measure requires the production of definitions. The reliability of this subtest for this age group is .86 . In addition, the Peabody Picture Vocabulary Test-R (PPVT), a measure of receptive vocabulary, was administered. The reported reliability of this test is .83 for this age group. An estimated I.Q. (ESTIQ) was obtained for each child. This score was based on the WISC-R Block Design and Vocabulary Subtests combined as suggested by Sattler (1982).

Experimental Measures. Eight nonsense words were created for use in this study. They were paired with definitions each of which had four semantic attributes. There are no one-word English equivalents for any of the experimental words. Pictures for each word were painted on $11^{\prime \prime} \times 14^{\prime \prime}$ white poster boards. A list of the words and definitions appears in Appendix A.

A game was created for use in this study. This Journey Game assessed short-term recall of the words learned in both the directed and incidental learning conditions. To play the game, a small remote-controlled robot with a tape deck was 
used. This robot played a recording of the game script, "A Journey to Another Planet", which had been taped by a local actor. During this game the children were asked to say specific experimental words in response to specific cues (definitions). A detailed explanation of the game appears in Appendix B.

An eight page booklet containing line drawings of the target words assessed the children's receptive vocabulary, or recognition of the words' referents. Each page contained line drawings of three learned words and two other objects. The children heard a word for each page and were asked to choose the correct referent. This was done in both short-term and long-term recognition conditions. A reproduction of the booklet appears in Appendix $\mathrm{C}$.

\section{Procedure}

Each child was met with individually in the first two sessions, and in small groups of three to five for a third session. The predictor measures and outcome measures were administered either by the principle investigator or any of three undergraduate research assistants. All word training was done by the principle investigator. To avoid examiner bias, the reading groups were not formed until all of the experimental measures had been completed.

Session 1: The Block Design and Digit Span subtests of the WISC-R, the vocabulary measures (VOCAB and PPVT) and the reading measures (ID and ATTACK) were administered to each subject. 
Session 2: Vocabulary training, the Journey Game (recall measure), and the booklet administration (short-term recognition measure) were conducted.

Vocabulary Training. The child was introduced to the concept of the game and to the task of learning the words. The words were put into two trial groups of three words each. The experimenter said a word, showed the child a picture of the object, and gave the definition. The child was then asked to repeat the word. After three words had been introduced in this manner, the trial blocks began. In each trial block the examiner stated the word and definition while presenting the appropriate picture. After the three words had been presented, the examiner showed the pictures, one by one, and asked for the words. If the child made an error, the examiner supplied the correct target and retaught the word. The same group of three words was then presented in another trial block. The order of the words within each block varied to avoid having the task become either predictable or tedious. A word was counted as learned if it was correctly produced on two successive blocks of trials. Each group of words was presented at least four times regardless of whether or not the criteria of two successful recalls for all three words had been met. A maximum of ten trials was selected as a cutoff. Children who did not reach the criteria of two consecutive successful trials for each word were not considered for inclusion in the reading groups. (Two children - one skilled reader and one less skilled reader, were eliminated from the 
reading groups on this basis). After the first group of three words was presented, the experimenter taught the child the second group of three words, following the same procedure.

Definition Testing. Immediately following the training, the examiner said the words and asked the child supply the definitions. Scores were obtained by counting the number of components of the definitions which the child supplied. If the child did not correctly pair the words and definitions during testing, the examiner paired the definition components given by the child with the appropriate target. This corrective feedback was given only after all six definitions had been tested.

In addition to the six words taught as described above, two other experimental words were introduced to the child. Both of these words were mentioned twice by the examiner, but were not deliberately taught. These two words are the stimuli for the fast mapping condition. Data from tasks using these words were collected in the Journey Game as well as in the recognition booklets. These data were analyzed separately.

A detailed description of the vocabulary training procedure appears in Appendix B.

Journey Game (Recall testing). Following the training phase children were individually introduced to the robot. Short-term recall was then assessed in a game. The Robot described an encounter with an object on the planet in terms which closely matched the learned definitions. The child was then asked to provide the correct target word for each given 
definition. All eight words were used in the game. The script of the Journey to Another Planet appears in Appendix C.

Booklet. Following the game, the short-term recognition booklet was introduced. Children were asked by the examiner to mark a particular target from a variety of foils on each page.

Session 3: A repeat of the booklet task was done at an interval of between one and three weeks from the initial presentation. In this presentation, the robot "said" the words. Intervals between Session 2 and Session 3 were evenly distributed between the reading groups.

Because of the poor performance of all children on the short-term recall task (Journey Game) in session 2, a planned long-term recall task was eliminated from session 3 .

\section{Scoring}

Directed Learning Condition Performance was scored in 6 areas in the directed learning condition:

1) Trials to criterion (TRIALS): The number of trials necessary to reach the criterion in the vocabulary training of Session 2 was assessed (possible trials: 4-20). The number of trials consists of the number of times a block of three words was presented until all three words in the block were learned.

2) Training errors (ERRORS): The number of errors made during vocabulary training during session 2 was calculated (possible scores: 0-36). The following were classified as errors: 1) 
a phonologically incorrect form of the target; 2) a phonologically correct or incorrect form of another experimental word; or 3) any other word or a failure to respond.

3) Accuracy of definition produced (DEFIN): The definition score for each word was calculated by tallying the number of definition components produced by the child (possible score: $0-24)$.

4 ) Short-term recall (RECALL): The number of words correctly recalled when presented with the definitions (during the Journey Game) immediately after having learned the words (possible scores: $0-6$ ).

5) Short-term recognition (RECOGNITION-ST): The number of targets correctly chosen in the booklet task during session 2 were tallied (possible scores: $0-6$ )

6) Long-term recognition (RECOGNITION-LT): The number of targets correctly chosen in the booklets during session 3 were calculated (possible scores: $0-6$ ).

\section{Incidental Learning Condition}

Children were also scored on 3 measures in the incidental learning condition (fast mapping), following the same procedures described above.

These areas were:

1) Short-term recall (I-RECALL): The incidentally learned words recalled in the Journey Game (Session 2) were tallied (possible scores: $0-2$ ).

2) Short-term recognition (I-RECOGNITOION-ST): The 
incidentally learned words correctly chosen in the booklet task (Session 2) were tallied (possible scores: 0-2).

3) Lonq-term recognition (I-RECOGNITION-LT): The incidentally learned words correctly chosen in the booklet task (Session 3) were tallied (possible scores: 0-2). The data from the incidental learning condition were analyzed separately from that of the directed learning condition. 


\section{RESULTS}

\section{Preliminary Analysis}

Preliminary tests were conducted to ascertain if there were in fact initial group differences in achieved vocabulary prior to the study. The skilled and less skilled reading groups were compared on the WISC Vocabulary and the PPVT measures, using the Analysis of Variance procedure (ANOVA). Using the WISC Vocabulary score as the dependent variable and reading group as the grouping variable, significant differences between skilled and less skilled readers were found $(\underline{F}(1,21)=4.96 \underline{p}<.04)$. Significant differences were also found when PPVT was used as the dependent variable, with reading group as the grouping variable $(\underline{F}(1,21)=4.62 \underline{p}<$ $.04)$

\section{Training Data}

Analysis of Data, $\mathrm{N}=56$ Several multiple regressions were performed to assess the relationships between the predictor variables [I.Q. (ESTIQ), short-term memory (DIGIT), and reading ability (ID, ATTACK)], and the outcome variables [(trials to criterion (TRIALS), vocabulary errors during training (ERRORS) and accuracy of definition (DEFIN)]. These Multiple Regressions were done with data from the entire pool of 56 subjects. The PPVT has often been selected as an estimate of intelligence in studies which require consideration of this factor. However in the present study the correlation between the PPVT and the ESTIQ was only .53 
$(N=56)$. In addition the report of Vellutino and Scanlon (1987), that good and poor readers matched on performance measures differed on vocabulary measures, suggests that pure verbal measures may not be a good estimate of intelligence for less skilled and disabled readers. Because of these considerations, two complete sets of multiple regressions were performed. One set of multiple regressions used the PPVT as the predictor variable for intelligence, the other used ESTIQ. The results were similar and the regressions which used the ESTIQ are reported below.

The Multiple Regressions were performed using The Stepwise procedure of SAS. This program selects .15 as the stay level for predictor variables. A complete description of this procedure can be found in the SAS manual (SAS, 1985).

A step-wise multiple regression was performed to explore the relationships of intelligence (ESTIQ), short-term memory (DIGIT), and reading ability (ATTACK \& ID), to the trials necessary to reach criterion (TRIALS). The predictor variables were ESTIQ, DIGIT, ATTACK, and ID, and the outcome variable was TRIALS.

The individual correlations of the predictor variables to the outcome variable TRIALS ranged from .04 to .13. When the variables were entered into a stepwise regression the resulting model included only the predictor variable ID, a measure of reading ability $\left(\mathrm{R}^{2}=.12, \underline{\mathrm{p}}<.01\right)$. After ID was entered, no other variable met the .15 significance level necessary for entry into the model. (See Appendix A, Table 1) 
To explore the relationships of intelligence, short-term memory and reading ability, to the errors made during training (ERROR), a second stepwise multiple regression was performed. The predictor variables were ESTIQ, DIGIT, ID, and ATTACK, and the outcome variable used was ERROR.

The individual correlations of the predictor variables to the outcome variable ERROR ranged from .05 to .13. When the variables were entered in a stepwise regression the resulting model included only the predictor variable ID, a measure of reading ability, $\left(\mathrm{R}^{2}=.12, \underline{\mathrm{p}}<.01\right)$. After ID was entered, no other variable met the .15 significance level necessary for entry into the model. (See Appendix A, Table 2)

A third stepwise multiple regression was performed to explore the relationships of intelligence, short-term memory and reading ability, to the accuracy of definition (DEFIN), a Multiple Regression. The predictor variables were ESTIQ, DIGIT, ID, and ATTACK, and the outcome variable used was DEFIN.

The individual correlations of the predictor variables to the outcome variable DEFIN ranged from .02 to .28. ESTIQ was by far the best predictor variable. When the variables were entered into a stepwise regression the resulting model included only the predictor variable ESTIQ, the measure of intelligence, $\left(R^{2}=.28, \underline{p}<.01\right)$. After ESTIQ was entered, no other variable met the .15 significance level necessary for entry into the model. (See Appendix A, Table 3)

To further investigate the factors affecting the 
definition score, the additional variable TRIALS was put into a second regression using the same procedure. This was done to ascertain if the number of times a child heard the words and definitions paired was a significant factor to the completeness of definition score. In brief, when the variables were put into the equation separately, the variable TRIALS accounted for little of the variance, and was not a significant factor.

Comparison of Skilled and Less-Skilled Reader Groups, N=22

To ascertain if contribution made by the reading ability would result in group differences between the skilled and less skilled reading groups on the outcome variables, several Analysis of Covariance (ANCOVA) procedures were performed. In these ANCOVAs, the ESTIQ score was used as the covariate. Although ESTIQ did not appear to substantially influence the learning of the words in the regression analysis, there were group differences in ESTIQ found between the skilled ( $M=$ 115.5) and less skilled $(M=99.5)$ readers. The ANCOVA procedure was selected to control for these initial group differences.

To ascertain if the skilled and less skilled reader groups differed on the number of trials necessary to reach criterion, a one-way ANCOVA, TRIALS x GROUP, with the ESTIQ as a covariate, was performed. Group differences were found $(\underline{F}(1,19)=4.11, \underline{p}<.06)$. To ascertain if the reader groups differed in the number of errors they made, a one-way ANCOVA, ERROR x GROUP, with the ESTIQ as a covariate, was performed. 
Group differences again emerged $(\underline{F}(1,19)=6.59, \underline{p}<.02)$. To ascertain if the groups differed in their ability to provide the definitions of the newly learned words, a one-way ANCOVA, DEFIN $x$ GROUP with ESTIQ as the covariate, was performed. This analysis failed to find any significant differences between the groups.

Recall and Recognition Data (trained words)

Analysis of Data, $N=56$. To explore the relationship of intelligence, short-term memory and reading ability to the ability to recall the words shortly after having learned them (RECALL), a stepwise multiple regression was performed. The predictor variables were ESTIQ, DIGIT, ATTACK and ID, the outcome variable used was RECALL.

The individual correlations between the predictor variables and the outcome variable, RECALL, ranged from .00 to .14. When the variables were entered into the step-wise regression the resulting model contained only the predictor variable ID, a reading measure $\left(\mathrm{R}^{2}=.14\right.$ p. $\left.<.01\right)$. After ID was entered, no other variable met the .15 significance level for entry into the model. (See Appendix A, Table 4).

All of the children had difficulty with this task, ( $N=$ $56, M=1.23)$, and the range of the achieved scores was narrow $(0$ - 4 out of a maximum of 6$)$. Because of this poor performance, a planned test of long-term recall was not conducted.

To explore the relationship between intelligence, shortterm memory and reading ability to pair the words with their 
referents (RECOGNITION-ST), a stepwise multiple regression was performed. The predictor variables used were ESTIQ, DIGIT, ATTACK and ID, the outcome variable used was RECOGNITION-ST.

The correlations of the predictor variables to the outcome variable ranged from .01 to .11 . When the variables were entered into the stepwise regression the resulting model included only ID, a reading measure, $\left(\mathrm{R}^{2}=.11\right.$ p.<.01.) After ID was entered, no other variable met the .15 significance necessary for entry into the model. (See Appendix A, Table 5).

Comparison of Skilled and Less Skilled Reader Groups, $\underline{N}=22$ To ascertain if the contribution of reading ability would result in group differences between the skilled and less-skilled reading groups on RECALI, an ANCOVA was performed. RECALL was used as the outcome variable, reading group was used as the grouping variable, and ESTIQ was used as the covariate; the results were not significant.

To ascertain if the groups differed in their ability to recognize the words referents over a short time span, the trained word short-term recognition data were entered in a one-way ANCOVA. This ANCOVA, RECOGNITION SCORE x GROUP, with ESTIQ as the covariate, was significant, $(\underline{F}(1,19)=7.75, \underline{p}<$ $.01)$.

A repeated measures ANOVA, for recognition scores of groups over time (short and long-term recognition) failed to produce any significant results. There was no difference between the relative ability of the groups to recall the words 
over time.

Retrieval and Recognition Data (untrained words)

As no subject was able to produce any of the untrained words in the recall situation, there was no analysis for this portion of the study.

A Chi-square was preformed, using the untrained recognition scores as the outcome variable. This analysis failed to find significant group differences, (See Appendix A, Table 6). 


\section{DISCUSSION}

The analysis of the data indicated that a positive relationship exists between reading ability and lexical acquisition ability. Reading ability predicted more of the accountable variance than either I.Q. (measured by either the ESTIQ or the PPVT) or short-term memory (measured by DIGIT) in measures of word learning (i.e. TRIALS, ERROR). This was found using the entire sample of 56 fourth grade children.

The predicted differences were found between the skilled and less skilled readers when the groups were compared on the measures TRIALS and ERRORS. This was true even when I.Q. was statistically controlled. These results indicate that less skilled readers do not learn the phonological labels for concepts as readily or as well as their skilled reading peers do. In contrast, the ability to grasp the conceptual attributes of the words, as measured by the definition score, was most highly influenced by I.Q. and not by reading ability. Both skilled and less skilled readers were incorporating the elements of each definition into a single conceptual unit, however, the less skilled readers were less able to retrieve the labels for these concepts during word learning. Interestingly, the number of trials required to learn the words to criterion had a near zero relationship to the definition scores. A possible interpretation of this result is that the number of times a child heard the words and definitions paired was not as important as I.Q. in the ability to incorporate the 
concept into the personal lexicon.

When recall performance of the entire sample was analyzed, there was little difference in the contributions of I.Q. and reading measures in the amount of variance accounted for. The reading measures were only slightly better predictors of retrieving the correct word when given the definition.

Group differences in the recall of the newly learned words did not emerge. It may be that good readers as well as poor readers find it difficult to retrieve newly learned words. Alternatively it may be that the words themselves were too numerous and/or complex for fourth grade children, or that the novelty of the situation hampered the children's ability to respond. Given the poor performance by all children on this measure, one or both of these alternative explanations seems to be a potential factor.

In an analysis of the recognition data, the differences in the amount of variance accounted for by either the reading measures or the ESTIQ was slight. The reading measures had only a small advantage as predictors. When I.Q. was statistically controlled, significant group differences in recognition were present. The groups were comparable, however, in the stability of their ability to recognize the words over time.

There were no differences in either the production or the recognition of the incidentally learned words. At least three factors may have influenced this outcome. First, this task 
was easier than recognition of the learned words. For each of these two words the choices presented were representations of the two incidental words, two learned words, and a 'wildcard' foil. The incorrect but plausible choices (seen before but not trained) was limited to one. A second possible factor is the limited range of scoring $0-2$. And finally the small sample size may have contributed to an increased Beta level in the statistical analysis.

If there are truly no differences in the rate of incidental word learning between skilled and less skilled readers, we must question why differences emerged in the directed learning phase. It is first of all possible that any significant difference is a statistical error. It had been decided that because of the small and uneven sample size, a MANCOVA would be inappropriate for the number of dependent variables. In addition, a high Type II probability was seen as particularly detrimental to such an exploratory investigation. The decision to run multiple ANCOVAs increased the probability of a Type I error.

A second possible explanation is that the less skilled readers have repeatedly experienced difficulty in school tasks. Although efforts were made to keep this from being an academic task by embedding it in the context of a game, the possibility must still be considered that the observed differences may have been due to expectations of failure and/or anxiety on the part of the less skilled readers. 
This second explanation is able to account for the observed group differences, but it is an unlikely as an explanation to account for the overall relationship between reading ability and word learning which emerged in the analysis of the entire sample.

It may appear to the reader that the less skilled readers did not do as well when many items to remember were presented (the six trained words), but were comparable to the skilled reader group when only two items were presented. However, in this study all eight words were presented during session two. The incidental words were mentioned before each of the two training blocks. This minimizes the possibility that the difficulty of the poor readers was due to less ability to learn multiple stimuli.

Therefore, support was found for the hypothesis which states that there are differences in lexical acquisition ability between skilled and less skilled readers. Learning of new vocabulary did differ between reading groups in a directed learning condition, and the failure to find differences in incidental learning may have been due to design or statistical problems.

Future studies are necessary to further explore the relationship of those factors which affect both reading and vocabulary acquisition. Before further studies are initiated, the nature of the errors made by the two groups must be analyzed and considered. Future investigations may then be constructed to more accurately target the underlying processes 
in which the two groups differ.

For instance, the children were required to repeat each item immediately after it had been introduced. If there were differences at this point it would point to possible differences in either the ability to perceive the word, or the ability to produce the words.

To more accurately assess where difficulty lies, several steps may be taken. First, tasks can be devised which compare the retrieval of a newly presented target word by the child with the child's ability to distinguish between the targets and foils. If the child is able to choose the correct word but is not able to repeat it accurately, it would suggest that perception and encoding are probably not the greatest area of difficulty. Second, the possibility exists that discrepancies in the ability to retrieve new words, relative to the ability to retrieve known words. There is evidence that less-skilled readers have greater difficulties than skilled readers in the area of lexical retrieval (Denckla and Rudel 1976a, 1976b). Whether or not this can account for the group differences in learning new words however is still to be explored.

Third, additional exploration of the relationship between short-term memory and learning new words can be undertaken. The present study used Digit Span as an estimate of short-term memory, and this variable was not a good predictor of word learning. However, there is evidence from Gathercole and Baddeley (1989) that Digit Span may not be an adequate measure of phonological memory. In addition Turner and Engle (1989) 
hypothesis that Digit Span may allow rehearsal and grouping strategies to circumvent working memory deficits. To more accurately assess working memory, they suggest a more complicated measure which involves a "background" task (see Turner \& Engle, 1989).

Future Research In follow-up research, the experience gained from the present study may serve as a guide. The possible inhibiting effect of equipment in the robot game (if a similar design is used) must be addressed. This can be done by giving the subjects a greater opportunity to become used to the equipment before the items to be scored are presented. This study used only a brief introduction before the two sample items were presented. Because of time limitations the session with the robot could not be extended to assure the children's familiarity and ease with the robot, although it was evident to the investigators that this would have been desirable in some cases.

Changes in the construction of the target words need to be considered. For the present study an attempt was made to construct two and three syllable words using a wide variety of phoneme combinations. There is a possibility that the resulting targets words were too complex for fourth-grade students. This difficulty might be addressed by matching the experimental nonsense words to common vocabulary items in the classroom curriculum, (i.e., number of syllables and types of consonant blends used).

In addition changes in the training procedures require 
consideration. Shorter sessions, with fewer items taught in each, might be preferable. This would allow for multiple sampling; in addition, a greater number of sampling items would result if the data from the sessions were combined.

An interesting variation in training would be to teach the words without the constant use of pictures found in the paired-associate design. This would make the task one which relies more on linguistic processes.

To address possible methodological problems, a larger sample size of skilled and less skilled readers would be desirable. Statistical procedures could them be conducted which would minimize the likelihood of both Type I and Type II error.

Incidental word learning must be more thoroughly explored. Although this may not seem appropriate given the present study's failure to discover a relationship between the reading measures and the outcome measures in this condition, it is a definite necessity. It is counter-intuitive that differences due to linguistic factors could exist in the trained condition and not the incidental condition. If there are truly no differences between the groups in incidental word learning, we must look for alternate factors to explain the observable differences in learning words in a training condition. Again, multiple sessions which would allow for a greater number of sampling items would be greatly desirable. This would diminish the differences between the conditions and also allow the difficulty level of the tasks for incidentally 
learned items to more closely approximate that of the taught items .

The results of this study, if they are confirmed and replicated, will be of interest in studying the linguistic factors common to reading and lexical acquisition, and in opening new avenues to explore in understanding language. In addition, there is potential benefit to educators in understanding the learning behavior of poor readers, as well as in planning and implementing the entire curriculum for the student who has a reading impairment with concomitant linguistic deficiencies. 
APPENDIX A

TABLE 1

Multiple Regression, Outcome Variable = TRIALS, $(N=56)$

Model $\mathbf{R}^{2}$ for Each Variable Entered Separately

Variable

ESTIQ

DIGIT Model $\mathrm{R}^{2}$

ATTACK

.04

.04

$2 . \frac{\mathrm{F}}{45} \quad \frac{\mathrm{p}}{12}>$

ID

.10

$2.86 \quad .10$

$5.72 \quad .02$

.13

$7.90 \quad .01$

Statistics for Entry, Steps $1 \& 2$

Step 1

Variable

ID

Model $\mathrm{R}^{2}$

.13

$7 . \frac{F}{90}$

$. \frac{\mathrm{p}}{01}>$

Step 2

Variable

ESTIQ

DIGIT

ATTACK

Model $\mathrm{R}^{2}$

.13

.15

.13

$\begin{array}{ll}\frac{\mathrm{F}}{20} & . \mathrm{p}> \\ 1.52 & .22 \\ 0.39 & .53\end{array}$

Final Model

Variable

ID

Model $\mathrm{R}^{2}$

.13

Partial $\mathrm{R}^{2}$

.13

$\stackrel{\text { F }}{7.90 \quad .01}$ 
TABLE 2

Multiple Regression, Outcome Variable=ERROR, $(N=56)$

yodel $\mathbf{R}^{2}$ for Each Variable Entered Separately

\begin{tabular}{|c|c|c|c|}
\hline Variable & Model $\mathrm{R}^{2}$ & $\underline{\mathbf{F}}$ & \\
\hline ESTIQ & .05 & $2 . \overline{43}$ &.$\overline{10}$ \\
\hline DIGIT & .05 & 2.77 & .12 \\
\hline ATTACK & .10 & 6.18 & .01 \\
\hline ID & .12 & 7.57 & .01 \\
\hline
\end{tabular}

Statistics for entry, Steps $1 \& 2$

Step 1

Variable

ID

Model $\mathbf{R}^{2}$

.12

$7 . \frac{\mathrm{F}}{57} \quad . \frac{p}{2}$

Step 2

Variable

ESTIQ

DIGIT

Model $\mathrm{R}^{2}$

ATTACK

.13

$0 . \frac{\mathrm{F}}{34} \quad . \frac{\mathrm{p}>}{56}$

.14

$1.21 \quad .27$

.14

0.64

.42

Final Model

Variable ID

Model $\mathrm{R}^{2}$

.12

Partial $\mathrm{R}^{2}$

.12

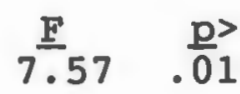


TABLE 3

Multiple Regression, Outcome Variable=DEFIN, $(N=56)$

Model $\mathbf{R}^{2}$ for Each Variable Entered Separately

Variable

ESTIQ

DIGIT

Model $\mathrm{R}^{2}$

.28

.03

.02

ATTACK

.08

$\begin{array}{rr}\underline{F} & \text { p> } \\ 21.47 & .00 \\ 1.54 & .21 \\ 1.25 & .26 \\ 5.05 & .03\end{array}$

Statistics for Entry, Steps 1 \& 2

Step 1

Variable

ESTIQ

Step 2

Variable

DIGIT

ATTACK

ID

Final Model

Variable

ESTIQ
Model $\mathrm{R}^{2}$

.28

$2 \frac{\text { F }}{1.47 \quad \frac{p>}{.00}}$

Model $\mathrm{R}^{2}$

.29

.28

.29

$\underline{\text { F }}$

0.05

.32

29

.82

.55

Model $\mathrm{R}^{2} \quad$ Partial $\mathrm{R}^{2}$

.28

.28

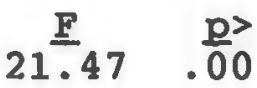




\section{TABLE 4}

Multiple Regression, Outcome Variable=RECALL, $(N=56)$

Model $\mathrm{R}^{2}$ for Each Variable Entered Separately

Variable

ESTIQ

DIGIT

Model $\mathrm{R}^{2}$

.09

5.

p>

ATTACK

.00

0.19

8.14

.02

8.94

.67

.09

.01

ID

Statistics for Entry, Steps 1 \& 2

Step 1

Variable

ID

Model $\mathrm{R}^{2}$

.09

$8 . \frac{F}{94}$

.00

Step 2

Variable

ESTIQ

DIGIT

ATTACK

Model $\mathrm{R}^{2}$

.17

.16

.16

$\begin{array}{rr}1.57 & . \mathrm{p}> \\ 1.19 & .21 \\ 1.51 & .28 \\ & .29\end{array}$

Final Model

Variable

ID

Model $\mathrm{R}^{2}$ .09

Partial $\mathrm{R}^{2}$

$\begin{array}{ll}\stackrel{F}{8.94} & \text { p> } \\ & .00\end{array}$ 
TABLE 5

Multiple Regression, Outcome Variable=RECOG, $(N=56)$

Model $\mathbf{R}^{2}$ for Each Variable Entered Separately

Variable

ESTIQ

DIGIT

Model $\mathrm{R}^{2}$

ATTACK

.09

.01

.07

ID

.11

$\begin{array}{ll}\stackrel{F}{5} & \text { p> } \\ 5.63 & .02 \\ 0.62 & .43 \\ 4.14 & .05 \\ 6.83 & .01\end{array}$

Statistics for Entry, Steps $1 \& 2$

Step 1

Variable

ID

Model $\mathrm{R}^{2}$ .11

$\frac{F}{6.83} \quad . \underline{p}>$

Step 2

Variable

ESTIQ

DIGIT

ATTACK

Model $\mathrm{R}^{2}$

.14

.11

.11

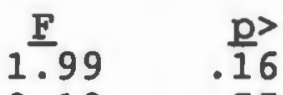

$0.10 \quad .75$

$0.10 \quad .74$

Final Model

variable ID

Model $\mathrm{R}^{2}$

Partial $\mathrm{R}^{2}$

$\frac{\vec{F}}{6.83} \quad . \underline{p 1}$ 
TABLE 6

Chi-Square

\begin{tabular}{l|c|c|c|c} 
& 0 words & 1 word & 2 words & total \\
$\begin{array}{l}\text { skilled } \\
\text { readers }\end{array}$ & 3 & 1 & 8 & 12 \\
$\begin{array}{l}\text { Iess- } \\
\text { skiled } \\
\text { readers }\end{array}$ & 0 & 3 & 7 & - \\
- - & 3 & 4 & 15 & -
\end{tabular}

$\underline{x}^{2}(2)=3.917 \underline{p}<.14$

N.B. cells have expected counts of less than 5 


\section{APPENDIX B}

Words

Directed learning:

Biffet

Corbealyon

Groshumble

Pogamer

Rimple

Taysum a bald, strange, friendly, animal a small, hairy, angry, bird soft, bouncy, bubble rain

a dark and noisy island floating above the ocean irregularly shaped, white berries; robot fuel

a smart, helpful, talking, fish

Incidental learning:

Bleximus

the planet name

Shillint

a two-wheeled space vehicle

\section{Training Session}

During the training session the following procedures and wording were used.

Examiner "As you know I'm making up a game using a robot named Robie; I would like you to play the game and then tell me what you think about it." [hold up planet card] "Robie is going on an imaginary journey to an imaginary planet. This beautiful planet, called Bleximus, is very far away; it is golden and has four purple moons." [display shillint card] "Robie is going there in his two-wheeled shillent. He will bring information about the planet back to the scientists on Earth. To do this he must enter the information into his memory banks. But sometimes Robie forgets the words he is 
supposed to remember. Your part in the game is to till Robie what he needs to remember. Would you like to try the game?" After the child's consent was obtained, s/he was introduce to the rest of the training materials.]

Examiner "These are pictures of what Robie will see on the planet, after you learn about them you will be able to help Robie."

[The cards were arranged in order of presentation. The picture of Bleximus was exposed again]

"Ready? Can you see the card if I hold it this way? I will show you the pictures and tell you about what Robie will see on Bleximus."

Block I

[The picture of planet was replaced by the picture of the Taysum. ]

"This is a taysum. A taysum is a smart, helpful, talking, fish. Now you say (try) the word please. Taysum."

[Any mispronunciations were then corrected until it could be ascertained the child had correctly perceived the word and was able to pronounce it. The taysum card was then removed, and after a few seconds, the next card was displayed. This procedure of presenting the picture, word, and definition, asking the child to repeat, and offering correction, was followed as each new word was introduced. There was always a slight pause between the exposure of the cards. It is to be noted that praised was given often, at least every $3 \mathrm{~min}-$ utes. ] 
"This is a picture of Rimple. Rimple is differently shaped white berries, it is used for robot fuel. Now you say the word please, rimple."

"This is a Corbealyon. A corbealyon is a small, angry, hairy, bird. Now you say ...etc."

[After this introduction to all three words, trial blocks began. Each card was exposed - in random order - and the child was asked for the name of the pictured object. All errors made by the child were immediately corrected as follows "that is not quite correct, it's a , you say it." If the child offered the definition instead of the word, the prompt was "yes, that's correct, but what is it called?" The cards, words, and definitions were presented again -in random order. The child was not asked to repeat the words however, following this the cards were displayed (individually) and the child was asked to provide the correct word with the prompt "what is this?". Each trial block of three words was presented at least four times, presentations discontinued only after two consecutive correct trials had been achieved for each word and only after the fourth exposure to the cards and definitions. Even if all words were not successfully learned, there was a maximum of ten trials. No child requested to stop.

Although the wording used was varied slightly (to avoid tedium) the underlined elements of the initial presentation were always included.

All errors were noted and corrected during training. 
Block II

"Now before Robie can take off in his shillent [display card] there are some more words to go through."

"This is a picture of a Biffet. A Biffet is a strange, friendly, animal who is bald. He doesn't have any hair. Now you say ...etc."

"This is pogamer. Pogamer is a dark and noisy flying island. Now you say ...etc."

"This is Groshumble. Groshumble is soft and bouncy bubble rain. Now you say ...etc."

If a subject commented on a feature of a target in the picture (color, shape, etc.) this was acknowledged only with a smile and a nod, or a comment such as "oh yes" without further elaboration or discussion. If a child was persistent in trying to discuss some feature the examiner responded with the comment "perhaps we will learn more about that when Robie takes the trip."

Note: In a preliminary testing of the robot it was thought that male voices reproduced more clearly than female voice. It was therefore decided to have Robie be a 'male' robot, referred to as "he".

By the end of this portion of the training the children had learned all of the trained words, and had been exposed to each incidental word twice and only twice. Definition testing

Immediately after both blocks of words had been gone thorough, the examiner asked for the definition of each word. 
Example, "what is a taysum? tell ne everything you know about taysum". A record was kept so that a score could be obtained of the number of definitional elements which the child produced for each word.

At the end of this task, any incorrect pairings of words and definitions were corrected. This was done by stating the elements of the given definition given that went together with the correct target word. For example, if a child said a Biffet is a small, talking, bird the correction was put into the following terms.

"There was something that you had twisted. A Corbealyon is a small bird, a Biffet is something else." Note that if a child included an incorrect descriptor it was not repeated in the correction. No further teaching of the words was attempted beyond this. 


\section{APPENDIX C}

Journey Game

In the Journey Game, the subjects heard the robot describe what he encounters on the imaginary planet. During the course of the game the robot asked the subjects to supply the six trained words as well as the two incidentally learned words.

Examiner "Now that you know the names of what Robie will find on the planet, we can play the game. Robie is going to tell you what he sees on his imaginary journey. Sometimes he may ask you questions, answer the best that you can. Even if you aren't quite sure, try to help Robie out with your very best guess."

When the Robot asked as question the tape was stopped (by remote control), to give the child time to answer. If the child did not respond to the robot's questions, the examiner encouraged with smiles and nods and the prompt "take a guess". Every effort was made to encourage response while ensuring that the situation did not become uncomfortable or unpleasant for the child. 


\section{Robie Script}

Hello! how are you today? [pause for response]. Are you here to help me? [pause for response]. I am ready to take a journey into space, it is time to take off!

\{spaces noises and lights -generated by robot\}

This journey is going very quickly. I should be able to see the planet soon - Yes! there it is right where I expected it to be. It is a lovely golden planet with four purple moons. I must enter into my memory that I have arrived, could you help me please? What is the name of this beautiful, golden planet? [pause for response]. \{noises and lights\}

Well here I am, I have landed on this beautiful island. Oh there are so many things to see here. Don't you think that I am a very lucky robot to be able to come here? [pause for response] .

I am near a beach. I can see a flying island in the air above the water, it is very dark and noisy. I must remember this, tell me the name of this dark and noisy flying island [pause for response].

I wish I knew how to get over there [pause for little voice] •

Little Voice "Fly to the island! Fly to the Island!"

Robot "Oh my goodness! Someone is telling me to fly to the island, but I don't see any one here. He must be smart. I will do as he says and fly to the island, but first I must remember this fish. Help me, tell me what smart and helpful 
talking fish is called [pause for response].

Here I am on the island. It is not so pretty here. It is scary and I hear scary noises. [scary noises]

Oh what could be making that noise? I see it is a little hairy bird. It looks angry. I must fly away but first tell me - what is the name of the small, angry, hairy, bird? [pause for response]

Well I will start back for home. Wait! I see a large green cloud in the sky. And something is falling from the cloud. Why it is raining bubbles! Oh they are very soft and bouncy. What is this falling from the sky? [pause for response ]

I'll go back now, first I have to call my two vehicle, now what is it called? [pause for response] I want to thank you for keeping me company and listening to me. Please take a sticker so that you will have a gift to remember this journey. \{lights, noises, robot gives sticker to children\} 


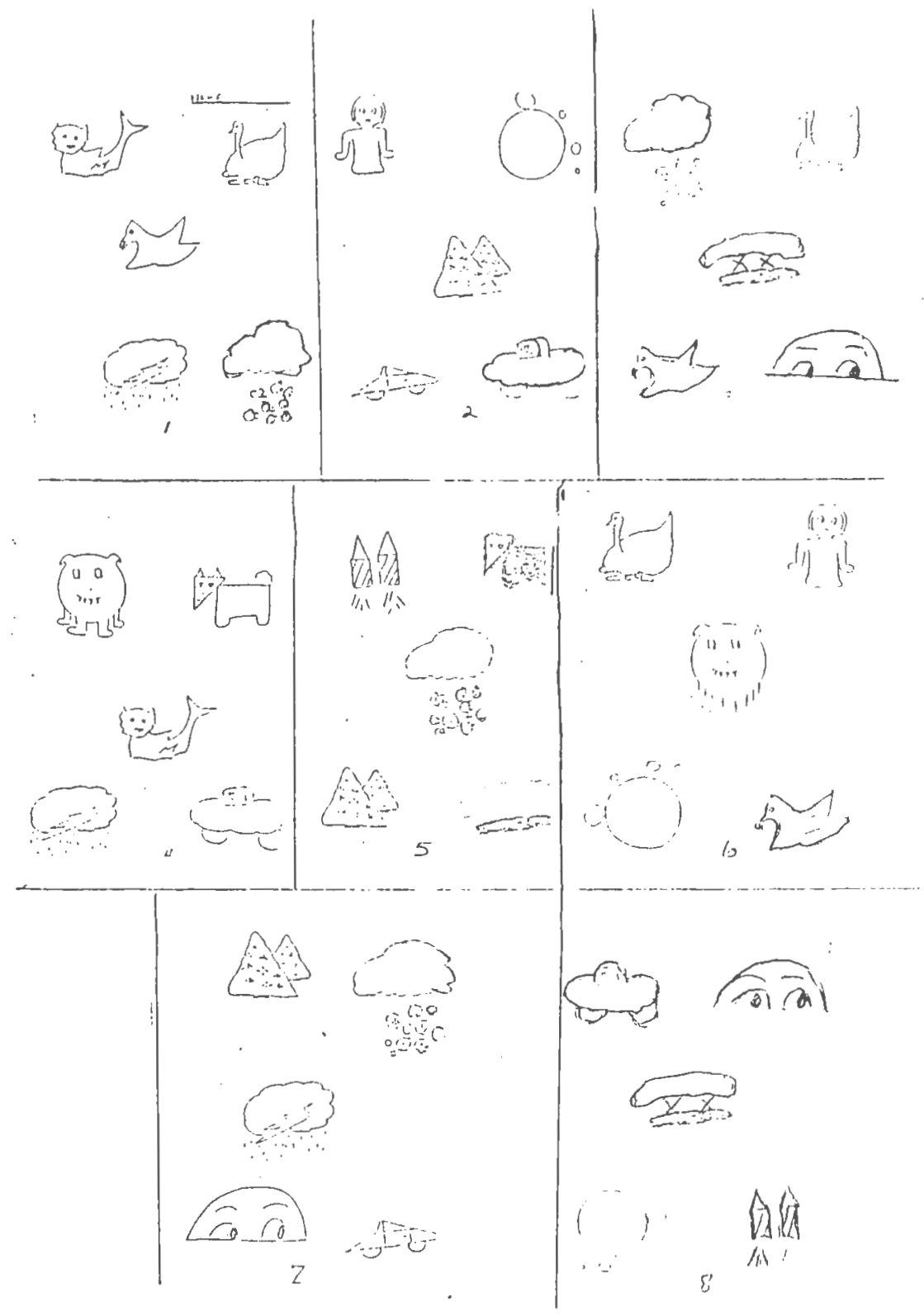




\section{BIBLIOGRAPHY}

Baddeley, A. (1986). Working Memory. Oxford: Clarendon Press.

Baddeley, A., Papagno, C., \& Vallar, G. (1988). When Long-term memory depends on short-term storage. Journal of Memory and Language, 27, 586-595.

Brady, S. (1986). Short-term memory, phonological processing and reading ability. Annals of Dyslexia, $36,138-153$.

Brady, S., Mann, V., \& Schmidt, R. (1987). Errors in Short-term memory for good and poor readers. Memory and Cognition, 15, 444-453.

Brady, S., Poggie, E., \& Rapala, E. in press.

Brady, S., Shankweiler, D., \& Mann, V. (1983). Speech perception and memory coding in relation to reading ability. Journal of Experimental Child Psychology, 35, $345-3 \overline{67}$.

Carey, S. (1978). The child as word learner. In M. Halle, Bresnan, J. \& Miller G. (Eds.) Linquistic Theory and Psychological Reality, (pp. 264-293). Cambridge, MA: M.I.T. Press.

Catts, H. (1986). Speech production/phonological deficits in reading-disordered children. Journal of Learning Disabilities, 19, 504-508.

Denckla, M., \& Rudel, R., (1976a). Naming of object drawings by dyslexic and other learning disabled children. Brain and Lanquage, $\underline{3}, 1-15$.

Denckla, M., \& Rudel, R., (1976b). Rapid 'autonimized' naming (r.a.n.): Dyslexia differentiated from other learning disabilities. Neuropsychologia, 14, 471- 479 .

Donahue, M. (1984). Learning disabled children's conversational competence: An attempt to activate the inactive listener. Applied Psycholinquistics, $\underline{5}, 21-$ 35 .

Dunn, L.M. (1981) . Peabody Picture Vocabulary TestRevised, Circle Pines, MN: American Guidance Service 
Gathercole, S., \& Baddeley, A. (1989). Evaluation of the Role of phonological STM in the development of vocabulary in children: A longitudinal study. Journal of Memory and Lanquage, 28, 200-213.

Godfrey, J., Sydral-Lasky, A., Millay, K., \& Know, C. (1981). Performance of dyslexic children on speech perception tests. Journal of Experimental Child Psychology, 32, 401-424.

Jenkins, J., Stein, M., \& Wysocki, K. (1984). Learning vocabulary through reading. American Educational Re search Journal, 21, 767-787.

Jordan, N. (1988). Language processing and reading ability in children: A study based on speech-shadow ing techniques. Journal of Psycholingistic Research, $17,357-377$.

Jorm, A. (1983). Specific reading retardation and working memory: A review. British Journal of Psychology, 74 , $311-342$.

Kail, R., \& Leonard, L. (1986). Word-finding abilities ni language impaired children. (ASHA Monographs, 25, ). Rockland, MD: American Speech-Hearing-Lan guageHearing-Association.

Katz, R., Shankweiler, D., \& Liebermann, I. (1981). Memory for item order and phonetic recoding in the beginning reader. Journal of Experimental Child Psychology, 32,

Liebermann, I., Mann, V., Shankweiler, D., \& Werfelman, .M (1982). Children's memory for recurring linguistic and nonlinguistic material in relation to reading ability. Cortex, 18, 367-376.

Liebermann, I. \& Shankweiler, D. (1985). Phonology and the problems of learning to read and write. Topical Issue: Remedial and Special Education, $\underline{6}$,

Morice, R. \& Slaugis, W. (1985). Language performance and reading ability at eight years of age. Applied Psycholinguistics, $\underline{6}, 141-160$.

Nagy, W., Anderson, R., \& Herman, P. (1987). Learning word meanings from context during normal reading. American Journal of Education Research, 24, 237-270.

Nelson, K. \& Warrington, E. (1980). An investigation of memory functions in dyslexic children. Journal of Psychology, 71, 487-503. 
Perfetti, C. (1985). Readinq Ability. NY: Oxford University Press.

Rudel, R. Denckla, M. \& Broman, M. (1978). Rapid silent response to repeated target symbols by dyslexic and nondyslexic children. Brain and Lanquaqe, $\underline{5}$, 52-61.

SAS Institute Inc. (1985). SAS User's Guide: Statistics, Version 5 Edition. Cary, NC: SAS Institute Inc.

Sattler, Jerome M. (1982). Assessment of Children's Intelligence and Special Abilities, Boston, MA: Allyn and Bacon.

Snowling, M. (1981). Phonemic deficits in developmental dyslexia. Psychological Research, 43, 219-234.

Snowling, M., Goulandris, N., Bowlby, M. \& Howell, P. (1986). Segmentation and speech perception in rela tion to reading skill: A developmental analysis. Journal of Experimental Child Psychology, 41, 489507 .

Turner, M. \& Engle, R. (1989) Is working memory capacity task dependent? Journal of Memory and Lanquage, 28, 127-154.

Vellutino, F. (1979). Dyslexia: Theory and Research, Cambridge, MA: M.I.T. Press.

Vellutino, F. \& Scanlon, D. (1987). Linguistic coding and reading ability. In S. Rosenberg (Ed.) Advances ni Psycholinguistics, (pp.1-69). NY: Cambridge University Press.

Vellutino, F., Scanlon, D. \& Tanzman, M. (1988). Lexical memory in poor and normal readers: Developmental differences in the use of category cues. Canadian Journal of Psychology, 42, 216-241.

Vogel, S. (1975). Syntactic Abilities in Normal and Dyslexic Children. Baltimore: University Press Park.

Wagner, R. \& Torgesen, J. (1987). The nature of phono logical processing and its causal role in the acquisition of reading skills. Psychological Bulletin, 101, 192212 .

Wechsler, D. (1974). Wechsler Intelligence Scale for Children-Revised. San Antonio, TX: Harcourt, Brace, Jovanavich.

Werker, J. \& Tees, R. (1987). Speech perception in severely disabled and average reading children. Canadian Journal of Psychology, 41, 48-61. 
Woodcock, R.W. (1983) Woodcock Reading Mastery Tests.

Circle Pines, MN: American Guidance Service.

Wolf, M. (1982). The word retrieval process and reading ni children and aphasics. In K. Nelson (Ed.), Child ren's Lanquage. $\underline{3}$. (pp.437-493). Hillsdale, NJ: Erl baum.

Wolf, M. (1984). Naming, Reading and the dyslexias: A longitudinal overview. Annals of Dyslexia, $34,87-$ 115 .

Wolf, M., Bally, H. \& Morris, R. (1986). Automaticity, retrieval processes, and reading: A longitudinal study in average and impaired readers. Child

Development, 57, 998-1000. 